\title{
Metathesis and Reanalysis in Ket
}

\author{
EDWARD VAJDA \\ Western Washington University
}

\section{Introduction}

This article identifies cases where metathesis and reanalysis have left idiosyncratic changes in the morphology of Ket, a critically endangered language of Central Siberia. Section 1 discusses basic typological features that reflect the language's distinctive genetic origin or developed from contact with typologically different morphologies. Section 2 examines five minor aspects of Ket word structure that seem anomalous in light of the known history of Yeniseian to show how each arose through metathesis or reanalysis. These features cannot be explained by simple descent or language contact, and failure to understand their true nature hinders a straightforward characterization of Ket typology. Section 3 explains how all five of these seemingly unconnected changes were triggered by a single rule of metathesis that operated on combinations of labial and non-labial consonants. Certain morphemes strongly affected by the metathesis later underwent semantic reanalysis.

The analysis reflects ongoing work compiling The Etymological Dictionary of the Yeniseian Languages (Vajda and Werner, in preparation). With fewer than 100 speakers, Ket is the last surviving member of the Yeniseian family and genetically isolated in North Asia. Internal comparative data from three of Ket's vanished southern relatives, Yugh, Kott, and Assan, along with external comparison with the distantly related Na-Dene family of North America (Vajda 2010), also appear in the article.

\section{Genetically Inherited and Contact-Induced Features in Ket}

Modern Ket in many ways presents a stark typological contrast to the suffixing agglutinative Ugric, Samoyedic, Turkic, Tungusic, and Mongolic languages spoken by the neighboring peoples of Inner Eurasia. Areally unique features of the phonology and morphology include phonemic tones, possessive proclitics, and 
Edward Vajda

a strongly prefixing verb. As Ket hunting groups took women as marriage partners from neighboring tribes over the centuries, influence from the surrounding suffixing morphologies modified certain inherited Yeniseian structural properties, though little borrowing of lexical material seems to have occurred (Vajda 2009). Ket provides an interesting case study of how areal pressure can alter native features to yield a uniquely blended typological profile. Morphology developed under areal influence involves mainly an elaboration of inflectional suffixes. Language contact most obviously affected noun inflection, but it also influenced the development of predicate agreement suffixes as well as a radical leftward shift of the semantic head position in finite verb morphology.

\subsection{Ket Phonemic Prosody}

Ket monosyllabic words contain four phonemic prosodemes consisting of an amalgam of melodic and non-melodic features. The tonal notation in (1-4) follows that used in Vajda (2004) and adopted by Georg (2007).

(1) High tone (high tone on half-long vowel, raised mid-vowel articulation)

$\begin{array}{ll}q \bar{o} ' j & s \bar{u} \cdot l \\ \text { 'aunt, uncle' } & \text { 'blood' }\end{array}$

(2) Laryngealized tone (pitch abruptly cut short by laryngeal stricture)

qo'j su'l

'wish' 'Siberian white salmon'

(3) Rising-falling tone (rising-falling pitch on a geminate vowel)

$\begin{array}{ll}\text { qój̀j } & \text { súùl } \\ \text { 'neighboring' } & \text { 'sled' }\end{array}$

(4) Falling tone (abruptly falling pitch on a short vowel)

q̀̀j sùl

'bear' 'hook'

Words of two or more syllables generally have regular non-melodic accent on their initial syllable. Tone was inherited from Common Yeniseian rather than borrowed, as none of the surrounding languages have phonemic tones. Vajda (2010) shows how distinctive pitch developed from erosion of consonant articulations in the syllable coda or, in the case of rising-falling tone, from elision of an intervocalic consonant.

The prosodic domain of tone in Ket is the phonological word, and tonal prosody helps distinguish clitic from affix boundaries. As a rule, suffixes merge prosodically with their host, affecting its tone, while clitics do not (Vajda 2008). 


\subsection{Preposed Possessive Markers}

To express possession, Ket uses pronominal markers separated from the following possessum noun by a clitic boundary.

$$
\begin{aligned}
& b \text {-sü'l d-sùl } \quad d a-q \bar{o} \cdot j \quad k-q \jmath^{\prime} j \quad \text { na-súùl } \\
& \text { 'my blood' 'her hook' 'his aunt' 'your (sg.) wish' 'our/your/their sled' }
\end{aligned}
$$

Anlaut consonant clusters occur only across a proclitic boundary.

Cognate possessive prefixes were present in the extinct Yeniseian languages (Werner 2005). Inherited from Proto-Yeniseian, they contrast typologically with the possessive suffixes typical of the surrounding families.

Possessive clitics take the following possessum noun as their host as in (5) only when no word precedes them in the same phonological phrase. Otherwise, they attach to the preceding word. In (6) the monosyllabic nouns $k \varepsilon^{\prime} t$ 'man, person', $h u$ 'n 'daughter', and $d \varepsilon$ ' $\eta$ 'men, people' have attracted the possessive marker as suffix, losing their inherent laryngealized tone:

(6) $k \varepsilon d-d a q \bar{o} \cdot j$,

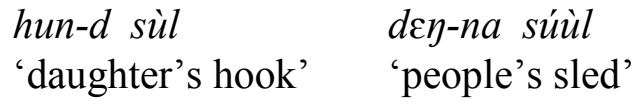

The tendency for pronominal possessive markers to attach to the preceding word probably arose through contact, given the general areal pattern of suffixes and root-initial words. The alternate explanation that these markers were originally suffixes on the possessor noun is not supportable, since they are not morphologically dependent on the presence of such a noun and readily encliticize to any available preceding word, even sentential adverbs. By contrast, possessive markers must be followed in context by the possessum noun, though separated from it by an equally obligatory clitic boundary. Apparently, these markers were originally simple prefixes that became special clitics to render the noun a root-initial phonological word in keeping with the root-initial morphologies of the surrounding languages.

In the next section, the same type of areal pressure will be shown to have influenced the finite verb morphology, where the rightmost agreement markers are also special clitics that frequently attach to the preceding word. This likewise creates root-initial structures out of finite verb forms, in typological accordance with the suffixing verbs found elsewhere in Inner Eurasia. 
Edward Vajda

\subsection{Polysynthetic Verb Structure}

A third Yeniseian feature that is strikingly unique in northern interior Eurasia is the family's traditionally prefixing verb morphology. All verbs displaying Ket and Kott cognates attesting to their membership in the oldest layer of the vocabulary are strongly prefixing. A general model of Ket finite verb structure appears in (7), with the three lexical slots marked in bold type.

(7) subject agr. - incorporate - agr. - thematic consonant(s) - 3p agr. tense/mood $-1 / 2$ agr. - root - animate-pl.subject agr.

As will become clear from the discussion below, this model ignores cases where metathesis has altered the original linear arrangement of morphemes.

Slots marked "agr." are used to express subject or object agreement. Based on which agreement slots are filled in each given stem, the Ket verbal lexicon can be divided into three productive transitive patterns and six intransitive patterns, with a residue of unproductive agreement marker configurations (Vajda 2009). The root is often preceded by several prefixes but only one suffix (animate-class plural subject agreement). A typical example appears in (8), where lexical morphemes are shown in bold type in keeping with the model introduced in (7):

\section{(8) d-ala-bo-kd-o-b-il-tay-in $(<* d-\boldsymbol{a l a}$-bo-kdb-ol-tay-in $)$}

3sbj-outside-1obj-thematic.consonants-past.tense-DRAG-pl.sbj

'They dragged me outside.'

Agreement and tense/mood affixes are interdigitated between the lexical morpheme (shown in bold type), making a linear representation of the verb stem difficult to achieve without recourse to a position-class formula of some sort. Ket verb forms also present other challenges for interlinear morpheme glossing. The function of thematic consonants such as $-k-,-d$ - and $-b$ - is often opaque, though these morphemes are lexical elements present in all forms of the given verb except where truncated by phonological rules. More will be said about thematic $-b$ - in 2.1 below, where it is shown to have metathesized ahead of the tense/mood vowel, complicating the original linear placement of thematic consonants before tense/mood markers. The expression of past tense in forms containing $-b$ - thus consists of linearly disconnected affixes, in this case $-o$ - and -il-. Note that the morpheme glosses in (8) reflect the "pre-metathesis" order of elements shown by the asterisked form.

As Vajda (2009) has argued, the suffixing languages spoken around Ket South Siberian Turkic, Samoyedic Selkup, Enets and Nenets, Tungusic Evenki, and Ugric Khanty - produced an interesting effect on Ket verb morphology. While preserving the original template, Ket innovated new patterns of verb stem 
creation in which the leftmost lexical slot - originally used to incorporate nouns, adjectives, or adverbs that semantically modified the verb root - contains an infinitive expressing the verb's primary lexical meaning. In such stems the original root slot contains a morpheme expressing aspect or transitivity. An example appears in (9):

d-bag-bo-k-ol-bet-in

3sbj-FIND-1 obj-thematic.consonant-past.tense-iterative-pl.sbj

'They used to find me (many times).'

Here the semantic head, expressed by the incorporated infinitive $b i g$ 'to find', stands near the beginning rather than the end of the verb form, as it did in (8). The morpheme -bet in root position originally meant 'do' or 'make', but here expresses iterativity rather than a concrete lexical meaning. A clitic boundary separates the subject marker $d$ - from the rest of the verb, so that $b i g$ 'to find' occupies phonological-initial position. See Reshetnikov and Starostin (1995:25) for the earliest identification of these markers as special clitics, and Vajda (2004:74) for the rules governing their phonetic realization.

The originally prefixing Ket verb has thus gradually manipulated the semantic possibilities of its inherited template to evolve a strongly suffixing structure, without rearranging or deleting any of the existing morpheme positions. All productive patterns of verb formation in Modern Ket require a lexical root in the incorporate slot. During fieldwork my native informants typically tried to deduce an unfamiliar verb's meaning by examining the incorporate rather than the morpheme in the original root position. Verbs without a recognizable lexical root in their initial syllable, such as example (8), belong to unproductive patterns, analogous to strong verbs in Germanic languages.

These innovations have converted all of the slots following the incorporate into de-facto suffixes, so that Modern Ket verb forms mimic the suffixing agglutinative verbs of neighboring languages. Vajda (2009) calls this process "typological accommodation" since it did not involve any borrowing of grammatical material or radical change in the verb's inherited polysynthetic structure.

\subsection{Person Agreement Suffixes}

Unlike Ket, the Kott finite verb innovated a series of subject person/number agreement suffixes. These new suffixes duplicates the meaning of the original subject person/number prefixes:

(10) i-te:n-u

2sg.sbj-LIE.DOWN-2sg.sbj.

'you (singular) lie down' 
Edward Vajda

In forms with plural subjects, they also duplicate the meaning of the older plural suffix -an inherited from Common Yeniseian, so that plurality is marked redundantly three times:

\section{(11)}

\section{on-te:n-ay-an-toy \\ 1pl.sbj.-LIE.DOWN-perfective/stative.-pl.sbj.-1pl.sbj. \\ 'we lie down'}

Multi-site person/number agreement developed as the Kott verb reoriented itself toward suffixation under areal influence. After the new verb-final person/number agreement series became productive, however, the original Common Yeniseian subject prefix and plural suffix seen in (11) were dropped in most verbs. The morpheme - $a \eta$-glossed 'perfective/stative' will be discussed in section 2.2 below.

Although Ket never innovated person agreement suffixes in its verb morphology, it did inherit from Common Yeniseian a series of predicate agreement suffixes that attach to adjectives and certain adverbs to mark subject person and number in locational or existential clauses lacking a finite verb of any kind. Three examples appear in (12):

\section{(12) soky-am soky-du soky-ay thick-3sg.inan. thick-3sg.masc. thick-3anim.pl. 'it is thick' 'he is thick' 'they are thick'}

Cognate predicate agreement suffixes were documented for the extinct Yeniseian languages, as well (Werner 2005). It is probable that these suffixes developed under areal influence, as modifiers assumed predicate head position in the absence of a conjugated verb form. This trait, already present in Common Yeniseian, was extended in Kott (but not Ket or Yugh) to the finite verb morphology.

\subsection{Nominal Case Suffixes}

Another feature that Yeniseian probably evolved through contact is its system of grammatical case suffixes. Ket cases semantically mirror those of neighboring languages and seem to have developed from an earlier system of postpositions (Vajda 2008). Some case suffixes require an augment identical to the possessive markers described in section 1.3.

(13) Ket ablative case of the noun qu's 'tent', with possessive augment -diqus-di-yal TENT-3p.inan.poss-abl.

Other case suffixes attach to the bare stem with no possessive augment. 
(14) Ket locative case of the noun qu's 'tent' qus-ka TENT-loc.

It remains unclear why some Ket case markers require a possessive augment while others do not; see Vajda (2008) for more discussion.

While pronominal possessive markers are inherited from Proto-Yeniseian, the system of nominal case suffixes seems to have evolved at least partly after the breakup of Common Yeniseian. Some case suffixes differ in shape across the daughter languages, reflecting a more recent development: compare the Kott ablative suffix - ča with Ket - $\eta a l$.

\section{Morphological Traits Arising from Metathesis or Reanalysis}

The previous section discussed salient features of Ket typology that reflect the family's distinct genetic inheritance (phonemic tone, possessive prefixes, prefixing polysynthetic verb) or which arose through contact (case suffixes, agreement suffixes on predicate adjectives, semantic reorientation of the finite verb template from prefixing to suffixing). The origin of certain minor, yet typologically striking idiosyncrasies in Ket morphology cannot be explained as simple inheritance or as byproducts of language contact. Earlier studies such as Vajda (2004) failed to account for them correctly. This section describes five odd morphological features that developed due to metathesis followed by reanalysis. These processes obscure the original, more regular patterns of word formation. Only when such effects are understood can a straightforward picture of Ket historical morphology emerge.

\subsection{The Mystery of Ket "Non-Agreement" - $b$ -}

Many Ket verbs contain an affix $-b$ - that regularly expresses agreement with an inanimate-class subject or object. This prefix stands between the thematic consonants and the verb root, occupying a position ahead of the tense/mood vowel but before the tense/mood consonant.

(15) Ket forms with inan.-class - $b$ - after the tense/mood vowel

a-b-qo da-k-o-b-in-tet

present-inan.sbj.-die 3 fem.sbj.-them.cons.-past-inan.obj.-past-hit

'it dies away' 'she hit it'

A comparison with the Kott forms in (16) suggests that the Ket inanimateclass marker $-b$ - has metathesized ahead of the tense/mood vowel: 
Edward Vajda

(16) Kott verb forms, with inan.-class $-b$ - before the tense/mood vowel

$\begin{array}{ll}\boldsymbol{b} \text { - } a-p i & \boldsymbol{b} \text { - } a-t^{h} i j-a \eta \\ \text { inan.-present-RIPEN } & \text { inan.-present-HIT-1sg.sbj. } \\ \text { 'it ripens' } & \text { 'she hit it' }\end{array}$

Kott preserved the pre-metathesis order of prefixes, with third-person agreement markers preceding the tense/mood markers, retaining the original linear order inherited from Common Yeniseian.

In all of these Ket and Kott verb forms, - $b$ - conveys agreement with an inanimate-class subject or object. However, some Ket verbs contain what appears to be the same affix that does not agree with any argument in the verb phrase but remains unchanged in all indicative forms, regardless of the subject or object.

This section will argue all cases of "non-agreement" $-b$ - arose through metathesis of a labial consonant originally occupying a different, but adjacent slot. Its origin has nothing in common with the homonymous inanimate-class agreement $-b-$.

In some of these cases, "non-agreement" - $b$ - arose when verb-root anlaut $b$ metathesized with the preceding perfective past-tense marker $-n$-:

(17) dabatomnet $<*$ da-ba-t-on-bet

3 fem.sbj-1obj-thematic.cons-past-UNDERSTAND

'she understood him'

(18) daatpines $<*$ da-a-t-in-bes

3 fem.sbj-3masc.obj-thematic.cons-past-DRAW

'she drew him'

Root anlaut $b$ - remains in its original location in the present-tense forms $d a-b a-t$ a-bet 'she understands me' and da-a-t-i-bes 'she draws him', where there is no preceding nasal to trigger the metathesis.

In the remaining cases, non-agreement $-b$ - represents a thematic consonant (probably the Proto-Yeniseian area prefix ${ }^{*} p$-) that metathesized ahead of the following tense/mood marker in stems containing another thematic consonant.

(19) da-don-ba-t-a-b-tet $<* d a-d o n-b a-t-p-a-t a d d^{j}$

3 fem.sbj-KNIFE-1obj-them.cons-area-present-HIT.ENDWISE

'she stabs me repeatedly'

Note that thematic ${ }^{*} p$ - voices to $b$ as a byproduct of this metathesis, for reasons that remain unclear. 


\section{Metathesis and Reanalysis in Ket}

Thematic $t$ - in (19) seems to express iterative meaning. When thematic ${ }^{*} p$ was stem's only thematic consonant, as in (20), it did not metathesize or voice to $-b$-, but instead yielded Ket $-h$ - and Yugh $-f$, the regular reflexes of ProtoYeniseian $* p$ :

\section{(20) Ket da-don-ba-h-a-tet (Yugh da-don-ba-f-a-tet $\left.{ }^{j}\right)<* d a-d o n-b a-p-a-t a d j$ 'she stabs me once' 3 fem.sbj-KNIFE-1obj-area-present-HIT.ENDWISE}

Accounting for labial metathesis is crucial for a correct description of the meaning, underlying shape, and original linear position of Ket verb morphemes. It is not correct to connect "non-agreement" $-b$ - etymologically with the homonymous inanimate-class agreement morpheme, as did Vajda (2003, 2004), who suggested it had innovated the non-agreement functions "applicative", "intensive", or "involuntary causative" in small numbers of verbs. In reality, Ket has no such categories derived from inanimate-class $-b-$.

Native speakers occasionally reanalyze "non-agreement" $-b$ - as the inanimateclass marker. My work with Ket informants turns up sporadic examples where a $3^{\text {rd }}$ person animate-class object marker replaces "non-agreement" $-b-$, even though the given forms contain the correct object markers in another location. For example, observe the canonical forms $d-o-g-d-a-b$-tay 'he drags him around' and $d-u-g-d-a-b-t a \eta$ 'he drags her around', where $-b$ - is the area prefix and $-o-$ and $-u-$ are the correct $3^{\text {rd }}$ person masculine and feminine-class object markers. These forms are sporadically replaced by $d-o-g-d-a j-t a \eta$ and $d-u-g-d-i j-t a \eta$. In the noncanonical forms, the redundant masculine-class marker $-a j$ - and feminine-class $-i j$ have replaced thematic $-b$-, which has obviously been falsely identified as an agreement marker.

Understanding how metathesis altered the surface position of inanimate-class $-b$ - and its lexical look-alikes simplifies the linear description of Ket verb morphology. Establishing the true identities of the various affix shapes $-b$ - in Ket and identifying their original locations as either entirely before or entirely after the two tense/mood markers, permits the eight-slot Ket verb model given in (7). This "pre-metathesis" linear model can replace the ten-slot template in Vajda (2004:45) or the nine-slot model in Reshetnikov and Starostin (1995:100). It also obviates the need to assign "non-agreement" $-b$ - to a different position class than the other thematic consonants.

\subsection{The Perfective/Stative Suffix}

A redundant plural suffix $-\eta$ seems to appear after a couple dozen basic verb roots in forms in forms conjugated with plural subjects. In some of these, plural agreement seems to be expressed redundantly up to four times, as in the Kott form in 
(11) or twice, as in the Ket verb $d$-in-ay-doq-y 'they flew' (cf. the singular form $d$-in-doq 'he flew'). This element actually turns out to be an ancient aspectual suffix that originally appeared in verbs denoting a change of state. Due to homonymy with the plural suffix, it was reanalyzed as a plural marker and deleted from most singular forms, though it occasionally remains fused to the root in both singular and plural forms, as in $h-a-b$-daqy 'it adheres', $d u$-h-a-daqy 'they get stuck' ( $d a q$ 'stick', 'adhere'); or $o-k-t-a-b-a-t u j u y ~ ' h e ~ h a n g s ~ s u s p e n d e d ', o \eta-k-t-a-$ $b$-a-tujuy 'they hang suspended' (to'j 'high up'). Verbs with this suffix belong to a semantic category Vajda $(2003,2004)$ called "stative-resultative" and Werner (1997) "passive-resultative". The Na-Dene cognate of this suffix was called the "perfective/stative" by Leer (2000) and the term is equally apt for Yeniseian. In both families it appears in verbs that express conditions arising from a prior action, as opposed to static states such as 'be long', or 'be red'. For more on the perfective/stative, see Vajda (2010:40-42, 49) or Leer (2000).

The Kott form in (21) illustrates the historical layering of agreement morphology in the verb complex. The underlined positions 2 through -1 were inherited into Proto-Yeniseian, as shown by external comparison with Na-Dene (Vajda 2010:36-60). The plural subject agreement position -2 must have been added by Common Yeniseian times, as it is present in Ket and Yugh as well as Kott. The Kott subject person/number agreement series in -3 is not found in Ket or Yugh and must have arisen under later Turkic influence:

$$
\begin{aligned}
& \frac{a l^{2}-o \eta^{1}-t e: n^{0}-a \eta^{-1}-a n^{-2}-t o \eta^{-3}}{2} \\
& \text { past }^{2}-1 \text { sbj.pl. }{ }^{1} \text {-LIE.DOWN }{ }^{0} \text {-perfective/stative }{ }^{-1} \text {-sbj.pl. }{ }^{-2}-1 \text { sbj.pl. }{ }^{-3} \\
& \text { 'we lay down' (past tense) }
\end{aligned}
$$

Reanalysis of the moribund perfective/stative suffix, which originally functioned to convey a resultant state, has created what appears to be a redundant series of plural suffixes fused to roots in some Ket and Kott verbs; see Krejnovich (1968:53-57) for more Ket examples of such forms. It is not correct, however, to posit two plural agreement suffix slots as an original Yeniseian feature.

\subsection{Plural Agreement Suffixes on Adjectives}

Ket is a head-marking prefixing language influenced by head-marking suffixing languages. There is no reason to expect inflections on attributive modifiers to have arisen through contact. Inflections in Ket normally appear on the finite verb or head noun, while modifiers are uninflected. However, about two dozen adjectives contain what appear to be plural agreement suffixes when modifying a plural noun: 


\section{Metathesis and Reanalysis in Ket}

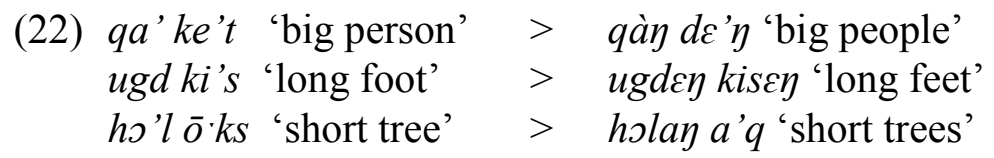

Evidence from Yugh shows that the apparent plural suffix $-\eta$ was originally an adjective derivational suffix that generally elided except where preserved through reanalysis as a plural marker in association with plural nouns due to its homonymy with the common noun plural suffix $-\eta$; both suffixes often contain epenthetic

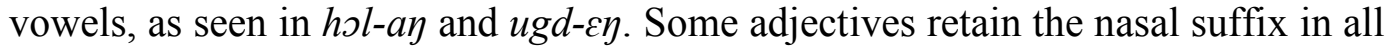
contexts, further demonstrating it was originally part of the stem and not an agreement marker. Two examples are Ket soky 'thick', udsky 'lazy', which modify either singular or plural nouns. Other adjectives show free variation between forms with or without this suffix. Once example is Yugh surbes

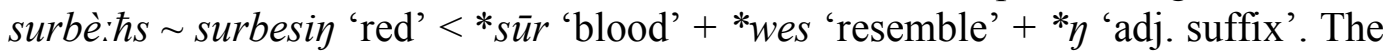
Ket cognate sulem 'red', which shows a more radical reduction, occurs with either singular or plural nouns - sulem t $\Lambda$ 's 'red stone', sulem t $\iota^{\prime} \eta$ 'red stones' - showing the nasal was originally part of the stem.

Recognizing this semantic reanalysis of the adjective derivational suffix * $-\eta$ makes it unnecessary to posit adjective number agreement as an original feature of Yeniseian - a highly idiosyncratic trait in a strongly head-marking language like Ket.

\subsection{Vestigial Infinitive Suffix}

Vajda (2010:60-63) provided evidence that Yeniseian once contained a productive infinitive suffix. This morpheme was identical to, and probably cognate with, the adjective suffix described in 2.3. It underwent the same pattern of reduction,

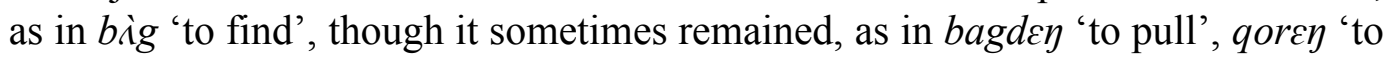
kill', and ensoky 'to forget' (cf. en 'thought', suk 'back', 'pushed back'). There are also occasional pairs where the suffixed form refers to multiple action.

(24) Ket bèr 'to make', 'to do' $\quad$ bercy 'to make, do (frequently)'

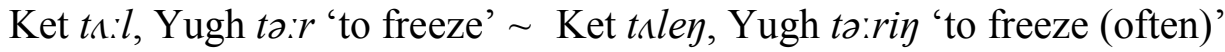

It is likely that here too we have an instance of reanalysis through false analogy with the plural suffix $-\eta$ found extensively in the nominal system.

\subsection{Ablaut Noun Plurals}

Yeniseian noun plural formation follows a typical North Asian suffixing pattern, e.g., $\bar{e} \cdot s$ 'god', esay 'gods'. But there are also occasional forms where plurality is expressed by tonal shift or other stem-internal changes. One example is Ket $s \bar{e} \cdot s$ 
'river', sàs 'rivers' and its Yugh cognate sēs 'river', sà: $\hbar s$ 'rivers'; note that pharyngealization $(\hbar)$ always accompanies falling tone in Yugh and was probably originally present in Old Ket, as well.

Early loanwords also offer examples of a final nasal eliding and falling tone (along with Yugh pharyngealization). Old Mongolian *qusan 'birch tree' probably approximates the original form that became Arin kus, Yugh $\grave{u} \cdot \hbar s$, and Ket $\grave{u} s$ 'birch tree'. Here the rounded vowel /u/, possibly labializing the following /s/, triggered metathesis with the following nasal.

Tonal patterns in irregular noun plurals resemble those of reduced infinitive and adjective stems, where attrition of a nasal suffix often left falling tone. The singular adjectives and plural nouns in (25) suggest that falling tone was caused by reduction of a nasal suffix:

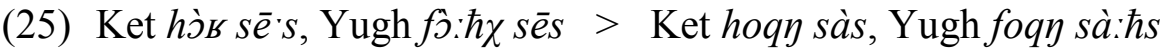
'deep river' 'deep rivers'

Reduction of the new rhymes that arose following metathesis sometimes left a

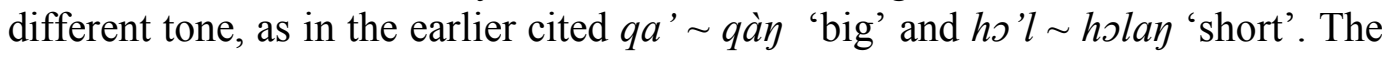
rules governing these reductions involve more than the metathesis itself and are beyond the scope of the present article. What is important here is identifying why suffixes metathesized in the first place.

If ablaut noun plurals arose from metathesis of a plural suffix followed by its reduction to pharyngealization and falling tone (or occasionally to another tone), it is unnecessary to posit root ablaut as a basic pattern in Yeniseian. Once metathesis is accounted for, Ket nominal inflection turns out to resemble the suffixing systems found elsewhere in Siberia.

\section{The Link Between Metathesis and Reanalysis}

Having described various cases of metathesis and subsequent coda reduction, as well as several instances of semantic reanalysis, it is possible to show how all of these changes developed on the basis of a single phonological rule that affected linear combinations of labial + non-labial or non-labial + labial elements. Reanalysis later followed where metathesis and reduction were so frequent as to leave only sparse remnants of what had formerly been a productive morpheme.

The reason noun plural suffixes were only occasionally replaced by root ablaut, while reduction of perfective/stative, adjective and infinitive suffixes was extremely common, becomes clear from the sound shape of these suffixes in Proto-Yeniseian. The perfective/stative, adjective and infinitive suffixes originally consisted of the labialized velar nasal $*_{-} \eta^{w}$. This sound metathesized with any preceding non-labial, so that these suffixes reduced more often than they remained intact. Plural suffixes consisted of non-labial $*_{-} \eta$ or $*_{-} n$ and metathesized 


\section{Metathesis and Reanalysis in Ket}

only in the much smaller number of stems that ended in a labial. When ProtoYeniseian $* \eta^{w}$ delabialized to $\eta$ in Proto-Ket-Yugh, the perfective/stative, adjective and infinitive suffixes that had originally avoided metathesis after another labial became homonymous with the plural suffix $-\eta$. They also became subject to the rule of metathesis they had earlier escaped, since now they were non-labial segments following a labial.

Labial metathesis occasionally produces free variants in Modern Ket, an example being the onomatopoetic qopqun and qoqpun, both meaning 'cuckoo bird'. If the new round of metathesis affecting the newly delabialized survivals of the perfective/stative, adjective and infinitive suffixes operated similarly, it would have produced pairs like Yugh surbè:ћs surbesiy 'red' that become susceptible to semantic redistribution based on false analogy with the common plural suffix -

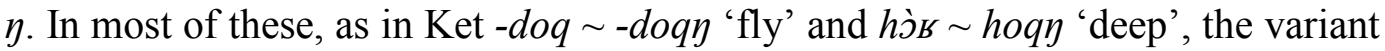
with $-\eta$ became associated with plurality and the suffixless form with singular meaning. In some cases, mostly after velars or uvulars as in soky 'thick', -daqy 'adhere', and ensoky 'to forget', the suffix remained regardless of whether the stem was associated with singular or plural meaning. In other cases, mostly after another nasal, attrition seems to have removed the suffix entirely, as in Ket sì'n 'old' and $k \wedge$ 'n 'light'. The phonological details of these processes remain to be worked out.

The existence of a Proto-Yeniseian series of labialized velars, crucial to this explanation, finds support from both internal and external comparative evidence (Vajda 2010:84-87). While * $\eta$ normally survived unchanged, as in genuine plural suffixes, labialized $* \eta^{w}$ elided in Kott and the closely related language Assan except where changed to another nasal by an earlier phonological process. For example, Kott $* \eta^{w}$ became $m$ before $p$ in the compound ujempul 'mosquito' < ujem 'long' + pul 'leg', whereas the simple adjective was recorded suffixless as $u i$ 'long' (cf. Ket ugd $\sim$ ugdey 'long', where $\eta$ is the reanalyzed adjective suffix). It delabialized to $\eta$ adjacent to $n$, as in (11) and (21), where the perfective/stative survived as -ay after te: $n$ 'lie down'. The sparsely documented Assan shows an example where the infinitive suffix ${ }^{*}-\eta^{w}$ dissimilated to $n$ after $\eta$ : tayn 'to see', though the Kott cognate $t^{h} a \eta$ was recorded without the suffix. External comparison with the Na-Dene perfective/stative shows a correspondence of Yeniseian $* \eta^{w}$ to Na-Dene ${ }^{*} \eta^{y}$, whereas Yeniseian ${ }^{*} n$ and ${ }^{*} \eta$ correspond instead to Na-Dene ${ }^{*} n$ and ${ }^{*} n$ ' (Vajda 2010:75-77).

Ket, Yugh and Kott noun plural suffixes regularly appear as $-\eta$ (mostly with inanimate-class nouns) or $-n$ (mostly with animate-class nouns), showing they reflect original $* \eta$ and $* n$, since labialized ${ }^{*} \eta^{w}$ would have mostly disappeared. Being non-labialized, plural suffixes underwent metathesis only after roots ending in a labial, a relatively infrequent occurrence. Being uncommon, ablaut plurals may have been subject to analogical leveling from the more frequent suffixed plurals. This might explain plurals such as Ket am-ay 'mothers' or $o b-a \eta$ 'fa- 


\section{Edward Vajda}

thers', where the plural suffix follows a labial coda, though the use of velar-nasal $-a \eta$ after such nouns (in place of the expected animate-class plural suffix $-n$ ) might have another explanation.

Some ablaut plurals seem to have arisen from non-labial roots. Ket sàs 'rivers' and Yugh sà: $\hbar s$ 'rivers' derive from the root noun *se's 'river', which contains no labial element. The expected plural would be *sesey. In such cases is the original root-final consonant may have been a labialized velar (the earlier coda of ${ }^{*} s \bar{e}$ 's 'river' was probably $* x^{w}$ ). This sound would have metathesized with the plural suffix, yielding an ablaut plural. Comparison with Na-Dene supports this, if Proto-Athabaskan *de $\check{s}$ 'river, sandbar' derived from earlier $* d e x^{w}$; cf. Vajda (2010:68) on the possible cognate status of these words. However, as mentioned earlier, a full account of Yeniseian irregular noun plurals involves rules in addition to metathesis and requires a separate study.

If the scenario presented here is correct, it would explain why metathesis occurred in some cases yet bypassed other, seemingly identical environments. It also explains why some suffixes became moribund and underwent reanalysis, while others remained productive in their original meaning. Considered with the evidence for labialized velar phonemes in Proto-Yeniseian, it becomes clear why reanalysis affected the perfective/stative, adjective, and infinitive suffixes so strongly, but left the seemingly homonymous noun plural suffix largely untouched. The reanalyzed suffixes were simply those that had lost their productivity through widespread attrition from an earlier application of the metathesis rule.

\section{Conclusion}

Correctly identifying the idiosyncratic effects of metathesis and reanalysis clarifies the origin of odd features of Ket morphology such as sporadic plural agreement in adjectival modifiers or redundant plural agreement suffixes in a subset of verbs. Identifying a series of labialized velars in Proto-Yeniseian and tracing their interaction with a rule of labial metathesis that still operates sporadically in Modern Ket, provides a cogent explanation for a variety of seemingly unrelated quirks in Yeniseian nominal and verbal morphology. It also demonstrates that Ket, while morphologically distinct from other North Asian languages, is not quite as typologically bizarre as previously characterized.

\section{References}

Georg, Stefan. 2007. A Descriptive Grammar of Ket. Part I: Introduction, Phonology, and Morphology. Kent, UK: Global Oriental.

Krejnovich, Jurij A., 1968. Glagol Ketskogo Jazyka [The Ket Verb]. Leningrad: Nauka. 
Leer, Jeff. 2000. The Negative/Irrealis Category in Athabaskan-Eyak-Tlingit. In Ted Fernald \& Paul Platero, eds., The Athabaskan Languages, 101-138. Amsterdam and Philadelphia: John Benjamins.

Reshetnikov, Kirill Ju., and Georgij S. Starostin. 1995. Struktura Ketskoj Glagol'noj Slovoformy [The Structure of the Ket Verb Form]. In Sergej A. Starostin, ed., Ketskij Sbornik, 7-121. Moscow: Jazyki Russkoj Kul'tury.

Vajda, Edward. 2003. The Ket Verb in Typological Perspective. Language Typology and Universals (STUF) 56.1/2:55-92.

Vajda, Edward. 2004. Ket. (Languages of the World/Materials 204). Munich: Lincom Europa.

Vajda, Edward. 2008. Head-Negating Clitics in Ket. In Edward Vajda, ed., Subordination and Coordination Strategies in North Asian Languages, 179201, Amsterdam and Philadelphia: John Benjamins.

Vajda, Edward. 2009. Loanwords in Ket. In Martin Haspelmath and Uri Tadmor, eds., Loanwords in the World's Languages: A Comparative Handbook, 471494, Berlin: Mouton de Gruyter.

Vajda, Edward. 2010. A Siberian Link to Na-Dene Languages. In James Kari and Ben Potter, eds., The Dene-Yeniseian Connection, 33-99 (Special issue of Anthropological Papers of the University of Alaska, New Series, Vol. 5.1/2).

Vajda, Edward, and Henirich Werner (in preparation). Etymological Dictionary of the Yeniseian Languages.

Werner, Heinrich. 1997. Die ketische Sprache. Wiesbaden: Harrassowitz.

Werner, Heinrich. 2005. Die Jenissej-Sprachen des 18. Jahrhunderts. Wiesbaden: Harrassowitz.

Edward Vajda

Western Washington University

Modern and Classical Languages, MS9097

Bellingham, WA 98225

edward.vajda@wwu.edu 